\title{
A Confounding Effect of Bacterial Titer in a Type III Delivery-Based Assay of Eukaryotic Effector Function
}

\author{
Morgan E. Carter, ${ }^{1}$ Adam J. Bogdanove, ${ }^{1,+}$ Roger W. Innes, ${ }^{2}$ and Roger P. Wise ${ }^{3,4}$ \\ ${ }^{1}$ Plant Pathology and Plant Microbe Biology Section, School of Integrative Plant Science, Cornell University, Ithaca, NY 14853, \\ U.S.A.; ${ }^{2}$ Department of Biology, Indiana University, Bloomington, IN 47405, U.S.A.; ${ }^{3}$ Corn Insects and Crop Genetics Research, \\ USDA-Agricultural Research Service, Ames, IA 50011, U.S.A.; and ${ }^{4}$ Department of Plant Pathology and Microbiology, lowa \\ State University, Ames, IA 50011, U.S.A.
}

Accepted 14 May 2018.

\begin{abstract}
This letter describes a newly discovered confounding effect of bacterial titer in a previously published type III delivery-based assay of the fungal effector BEC1019. The original publication (Whigham et al. 2015) has been retracted as a consequence of this discovery. Here, we tabulate the affected and unaffected figures and conclusions in the original publication and briefly reflect on potential pitfalls to bear in mind when designing experiments that use bacterial type III secretion to characterize eukaryotic effectors.
\end{abstract}

Delivery by bacterial type III secretion is a powerful and increasingly common approach for screening fungal and other eukaryotic candidate effectors in planta (Ittig et al. 2015; Sharma et al. 2013; Upadhyaya et al. 2014; Yin and Hulbert, 2010), especially those of genetically intractable organisms like obligate biotrophs. We used this approach in a study of the effector BEC1019 of the barley powdery mildew pathogen Blumeria graminis f. sp. hordei (Whigham et al. 2015). In revisiting some of the results of that study, however, a new investigator in our group (M. E. Carter) discovered a confounding effect of the titer of the bacterium that we had not controlled for, rendering some of the experimental results presented in the paper inconclusive. For this reason, we have retracted the paper (Whigham et al. 2015). We are writing this letter to provide details, including a tabulation of affected and unaffected figures and conclusions in the paper, and a brief reflection on potential pitfalls to bear in mind when designing experiments that use a bacterial type III secretionbased delivery assay to characterize eukaryotic effectors.

For our type III secretion-based assays, we used Xanthomonas campestris pv. raphani $756 \mathrm{C}$ to deliver the candidate Blumeria graminis effector BEC1019, fused to the type III secretion signal domain of the Xanthomonas effector AvrBs2, into barley cells, following syringe-infiltration of leaves. When BEC1019 was present, we found a reduction in hypersensitive reaction (HR) induced by either of two elicitors, Xanthomonas oryzae pv. oryzicola BLS256 (Fig. 2; Table 1) or the Pseudomonas effector AvrPphB, also delivered using X. campestris pv. raphani 756C (Fig. 3, Supplementary Fig. S2) (Whigham et al. 2015). We concluded that BEC1019 is a nonspecific host defense suppressor. By testing BEC1019 mutants in this system,

${ }^{\dagger}$ Corresponding author: Adam J. Bogdanove; E-mail: ajb7@cornell.edu

This article is in the public domain and not copyrightable. It may be freely reprinted with customary crediting of the source. The American Phytopathological Society, 2018. we also concluded that its ETVIC motif is important for this function (Fig. 6; Tables 3 and 4). Following publication of the paper, M. E. Carter found, however, that at a low titer (optical density at $\left.600 \mathrm{~nm}\left[\mathrm{OD}_{600}\right]=0.05\right)$, equivalent to that of $X$. campestris pv. raphani $756 \mathrm{C}$ expressing AvrPphB in Figure 3, X. campestris pv. raphani $756 \mathrm{C}$ by itself consistently elicits an HR-like response. She then tested the effect of $X$. campestris pv. raphani $756 \mathrm{C}$ by itself at the higher titer $\left(\mathrm{OD}_{600}=0.40\right)$ used for $X$. campestris pv. raphani $756 \mathrm{C}$ carrying the BEC1019 or control constructs in Figures 2 and 3. She found, surprisingly, that, at the higher titer, $X$. campestris pv. raphani $756 \mathrm{C}$ variably does not elicit any HR-like response. The results presented in Figures 2, 3, and 6 in Whigham et al. (2015) include neither of these controls and are thus inconclusive. When those experiments were repeated with the controls for effects of bacterial titer, we could not conclude that BEC1019 can suppress HR triggered by $X$. oryzae pv. oryzicola BLS256 or AvrPphB or that the ETVIC motif is involved in this function.

In our original study (Whigham et al. 2015), we used AvrPphB as a specific HR elicitor to test defense suppression by BEC1019 because we had found, following a screen of 73 diverse barley lines, that several lines apparently recognize AvrPphB delivered by $X$. campestris pv. raphani $756 \mathrm{C}$. In light of our new observation that $X$. campestris pv. raphani $756 \mathrm{C}$ alone at $\mathrm{OD}_{600}=0.40$ usually but not always elicits no response, the results of that screen can no longer be assumed to be valid. Indeed, when the screen was partially repeated, we found variability that had not been recorded before. The data presented in the paper are, therefore, insufficient to conclude that the barley lines we reported to undergo HR to AvrPphB do so.

Unaffected in our original study (Whigham et al. 2015) are the Barley stripe mosaic virus virus-induced gene silencing experiment (Fig. 1), showing that silencing of BEC1019 reduces fungal growth in barley, and the sequence analysis identifying BEC1019 across fungal species and finding two conserved motifs and variable residue correlation with lifestyle (Figs. 4, 5, and 7). The conclusions that BEC1019 contributes to pathogenicity, as quantified by haustorial index, and that it is broadly conserved across major fungal taxa thus stand.

Our failure to include all necessary controls for the type III secretion assays perhaps brings to light a fervor for the approach that must be tempered by careful consideration of caveats, one being unexpected titer-dependent effects of the bacterium itself, which we had not controlled for. We suggest that investigators using this approach as well as reviewers be aware of such occurrences. There are at least two other, more general caveats. 
One, relative to delivery by the fungus from which an effector originates, when the effector is delivered through a bacterial type III secretion system, there could certainly be differences in amount or location of the effector delivered or differences in posttranslational modifications of the effector. Two, effectorless mutants (Wei et al. 2015) or nonphytopathogenic bacteria (e.g., Pseudomonas fluorescens) impact plant immune signaling and this impact can confound interpretation of the functions of delivered heterologous effectors. In some studies, though, elicitation of plant defense by the delivery bacterium has been used advantageously to study function of the heterologous effector (e.g., by Ramachandran et al. [2017]).

We by no means wish to discourage use of bacterial type III delivery for identification and characterization of eukaryotic effectors. With appropriate consideration of caveats such as those mentioned above and careful design of properly controlled experiments, type III secretion-based delivery can be a powerful tool. Indeed, we have recently adopted an effector-less mutant derivative of Pseudomonas syringae pv. tomato DC3000, D36E (Wei et al. 2015), for delivery. D36E on its own consistently induces no $\mathrm{HR}$ in any of more than 150 barley lines we have tested, at low or high titers. Using D36E for delivery, we have discovered that BEC1019 in this system is not able to suppress HR caused by X. oryzae pv. oryzicola BLS256 or by DC3000 (which elicits robust HR in all barley lines tested). Further, we have repeated and expanded our screen for AvrPphB-responsive barley lines, using $\mathrm{D} 36 \mathrm{E}$ to deliver AvrPphB or a protease activity-deficient mutant derivative, AvrPphB(C98S) (Shao et al. 2002), as a control. We have found several lines that respond specifically to AvrPphB. These findings are the basis of a different study, currently in review for publication.

\section{LITERATURE CITED}

Ittig, S. J., Schmutz, C., Kasper, C. A., Amstutz, M., Schmidt, A., Sauteur, L., Vigano, M. A., Low, S. H., Affolter, M., Cornelis, G. R., Nigg, E. A., and Arrieumerlou, C. 2015. A bacterial type III secretion-based protein delivery tool for broad applications in cell biology. J. Cell Biol. 211: 913-931.

Ramachandran, S. R., Yin, C., Kud, J., Tanaka, K., Mahoney, A. K., Xiao, F., and Hulbert, S. H. 2017. Effectors from wheat rust fungi suppress multiple plant defense responses. Phytopathology 107:75-83.

Shao, F., Merritt, P. M., Bao, Z., Innes, R. W., and Dixon, J. E. 2002. A Yersinia effector and a Pseudomonas avirulence protein define a family of cysteine proteases functioning in bacterial pathogenesis. Cell 109: 575-588.

Sharma, S., Sharma, S., Hirabuchi, A., Yoshida, K., Fujisaki, K., Ito, A., Uemura, A., Terauchi, R., Kamoun, S., Sohn, K. H., Jones, J. D. G., and Saitoh, H. 2013. Deployment of the Burkholderia glumae type III secretion system as an efficient tool for translocating pathogen effectors to monocot cells. Plant J. 74:701-712.

Upadhyaya, N. M., Mago, R., Staskawicz, B. J., Ayliffe, M. A., Ellis, J. G., and Dodds, P. N. 2014. A bacterial type III secretion assay for delivery of fungal effector proteins into wheat. Mol. Plant-Microbe Interact 27: 255-264.

Wei, H.-L., Chakravarthy, S., Mathieu, J., Helmann, T. C., Stodghill, P., Swingle, B., Martin, G. B., and Collmer, A. 2015. Pseudomonas syringae pv. tomato DC3000 type III secretion effector polymutants reveal an interplay between HopAD1 and AvrPtoB. Cell Host Microbe 17:752-762.

Whigham, E., Qi, S., Mistry, D., Surana, P., Xu, R., Fuerst, G. S., Pliego, C., Bindschedler, L. V., Spanu, P., Dickerson, J. A., Innes, R., Nettleton, D., Bogdanove, A. J., and Wise, R. P. 2015. Broadly conserved fungal effector BEC1019 suppresses host cell death and enhances pathogen virulence in powdery mildew of barley (Hordeum vulgare L.). Mol. Plant-Microbe Interact. 28:968-983.

Yin, C., and Hulbert, S. 2010. Prospects for functional analysis of effectors from cereal rust fungi. Euphytica 179:57-67. 